\title{
The impact of calibration on medical devices performance and patient safety.
}

\author{
Altayyar Saleh $\mathbf{S}^{1 *}$, Mousa $\mathrm{MA}^{2}$, Alfaifi $\mathrm{AM}^{2}$, $\operatorname{Negm~} \mathrm{AE}^{2}$, Ali $\mathrm{MO}^{2}$ \\ ${ }^{1}$ Department of Biomedical Technology, College of Applied Medical Sciences, King Saud University, Riyadh, Saudi \\ Arabia \\ ${ }^{2}$ Healthcare Technology Management Administration, King Fahad Medical City, Ministry of Health, Riyadh, Saudi \\ Arabia
}

\begin{abstract}
Hospitals and health care providers are striving to reduce health care cost without compromising the quality of health care and appropriate medical diagnosis. They are becoming more aware of the importance of medical devices calibration in their health care facilities, and the impact it has on both the quality of health services provided to the patients, and patient's safety. Healthcare providers are beginning to realize that the maintenance of medical devices alone, without assuring proper calibration, may not be sufficient enough to ensure proper function, adequate and reliable measurements. Accurate and reliable measurements are crucial for appropriate medical decisions. On the contrary, un-calibrated medical devices may lead to imprecise measurements. These measurements will have a significant negative impact on the quality of the healthcare provided to patients and might increase the healthcare cost by subjecting patients to excessive medical treatment. The study was conducted on a representative sample of $20.5 \%$ from total asset (1034) of high risk medical devices representing 6 devices categories. The objective of this study is to examine the impact of calibration of medical devices on performance and patient's safety by investigating devices performance against international standard reference or manufacturer recommendations. $34 \%$ of the sample failed the visual test, $5 \%$ failed the safety test, and $58 \%$ failed the performance test. However, it is important to note that there was no death or serious incidents associated with these devices. In conclusion, these devices do not meet the international standard and continued use of such devices can compromise patient's safety.
\end{abstract}

Keywords: Patient's safety, Performance, Calibration, Medical devices accuracies.

Accepted on May 07, 2018

\section{Introduction}

The medical devices industry has grown rapidly and incessantly over the past century. The sophistication and complexity of the designed instrumentation is nowadays rising and, with it has also increased the need to develop some better, more effective and efficient maintenance processes, as part of the safety and performance requirements [1]. For the health industry, be it hospitals or manufacturers of medical devices, nothing counts more than the safety of a patient [2]. Therefore all quality conscious hospitals consider the periodic testing and calibration of devices, a permanent feature in their quality control regimen that they strictly adhere to. It is a significant mark to their dedication and commitment to quality and continuous improvement. Testing and calibration of devices ensures accuracy, effectiveness in diagnosis and treatment and long life of devices, which ultimately enables one to achieve the highest degree of quality control and patient safety. Medical errors are a recognized cause of harm in the health care system, but clinical measurement errors are seldom, if ever, identified as causes of adverse events [3]. In recent years, a growing number of patients have suffered from adverse events due to medical devices malfunction [4]. In addition to knowledge and experience of medical doctors, correct diagnosis and appropriate patient treatment largely depend on accuracy and functionality of medical devices. In a large number of serious medical situations, devices proper functionality of medical devices is crucial for patients. Therefore it is necessary to carry out as strict and independent testing of functionalities of medical devices as possible and to obtain the most accurate and reliable diagnosis and patient treatment [5]. The objective of this paper is to examine the impact of calibration on medical devices performance and patient's safety by investigating the performance of selected sample of medical devices against international standard reference or manufacturer recommendations.

\section{Methodology}

This research is designed to determine the clinical significant of un-calibrated medical devices in health care facilities. Further, the research will investigate and evaluate the activities 
of medical devices function against standard reference. Due to the impact of medical devices bad performance on patient's safety and the quality of health services provided to patients, the main target here is patient safety and medical devices performance. The test is performed on site in different clinical departments of a major hospital in Saudi Arabia. The department and devices were selected randomly as per their availability. The concept of research project design and methodology are shown in Figure 1.

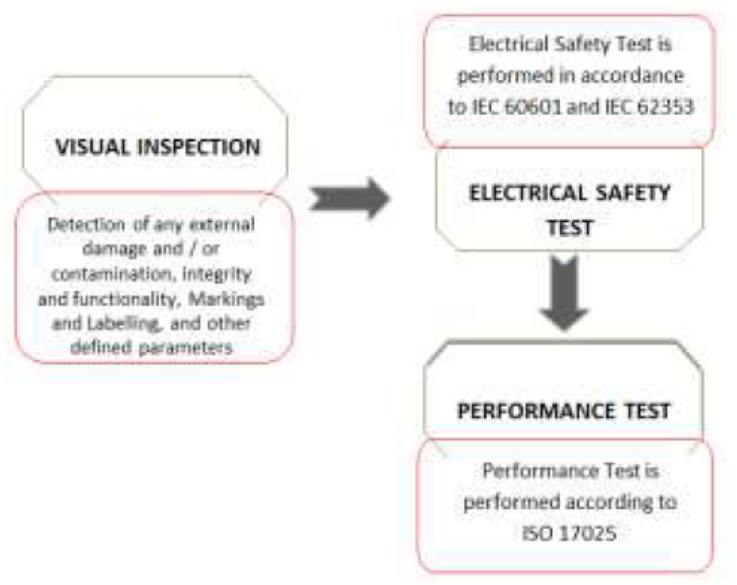

Figure 1. Research design flowchart.

The study was conducted on a representative sample of $21 \%$ from total asset (1034) of high risk medical devices representing 6 devices categories. The devices are infant incubators, transport incubators, warmers, defibrillators, electrocardiogram (ECG) and vital signs monitor. Each of the devices under test (DUT) was subjected to a sequence of tests in accordance to IEC60601, IEC 62353, and ISO 17025 [6-8]. The sequence of test cycle include: visual inspection, electrical safety testing and performance test. The process of visual inspection is not clearly defined by IEC 60601, however it is a relatively easy procedure to make sure that the medical devices in use still conforms to the specifications as released by the manufacturer and has not suffered from any external damage and/or contamination [9]. These can include the following inspections: housing enclosure, contamination, cabling, fuse rating (check correct values after replacement), markings and labelling, and Integrity of mechanical parts.

Electrical safety test is performed in accordance to IEC 60601 and IEC 62353. Performance Test is performed according to international standards or manufacturer recommendations by using the suitable calibrated and traceable standard reference(s) or test devices $[10,11]$. Both the safety and performance of the DUT will be subjected to assessment based on technical comparisons against international standards or manufacturer recommendations, which sets the limit for pass and fail acceptance criteria [12-21]. The limit used to decide the DUT pass/fail criteria is shown in Table 1 . The test is performed by ISO 17025 certified biomedical engineers, who are also certified by Fluke biomedical advantage training on the use of test equipment. The test equipment used is calibrated and is shown in Table 2. These test equipment were found to meet Fluke biomedical manufacturing specifications as per the test equipment calibration certificate.

Calibration measurements are traceable to the National Institute of Standards and Technology (NIST). Devices for which there are no NIST calibrations standards are measured against in-house performance standards using accepted test procedures. The results obtained from the test equipment are recorded in a hardcopy checklist and at the same time, a copy of the electrical safety automatic test sequence is saved in the analyzer and later printed and attached to the hard copy reports to guarantee the data traceability with electronic archival system.

Table 1. Pass/fail criteria.

\begin{tabular}{|c|c|c|c|}
\hline Measurements & Standard & Limit & \\
\hline Incubator IEC60601-2-19/60601-2-20 & & Baby & Transport \\
\hline Sound level & 201.9.6.2.1.101 & $\leq 60 \mathrm{~dB}$ & $\leq 60 \mathrm{~dB}$ \\
\hline Stability of temp & 201.12.1.101 & $\pm 0.5^{\circ} \mathrm{C}$ & $\pm 1.0^{\circ} \mathrm{C}$ \\
\hline Uniformity of temp & 201.12.1.102 & $\pm 0.8^{\circ} \mathrm{C}$ & $1.5^{\circ} \mathrm{C}$ \\
\hline Skin temp & 201.12.1.103 & $\pm 0.3^{\circ} \mathrm{C}$ & $\pm 0.3^{\circ} \mathrm{C}$ \\
\hline Accuracy of indicator & 201.12.1.105 & $\pm 0.8^{\circ} \mathrm{C}$ & $\pm 1.5^{\circ} \mathrm{C}$ \\
\hline Temp control accuracy & 201.12.1.106 & $\pm 1.5^{\circ} \mathrm{C}$ & $\pm 1.5^{\circ} \mathrm{C}$ \\
\hline Overshoot & 201.12.1.108 & $\leq 2^{\circ} \mathrm{C}$ & $\leq 2^{\circ} \mathrm{C}$ \\
\hline $\mathrm{RH}$ accuracy & 201.12.1.109 & $\pm 10 \%$ & $\pm 15 \%$ \\
\hline Air flow & 201.12.1.111 & $\leq 0.35 \mathrm{~m} / \mathrm{s}$ & $\leq 0.35 \mathrm{~m} / \mathrm{s}$ \\
\hline \multicolumn{4}{|l|}{ Radiant warmers } \\
\hline Distribution accuracy & 201.9.6.2.1.102 & & $\pm 2^{\circ} \mathrm{C}$ \\
\hline
\end{tabular}


The impact of calibration on medical devices performance and patient safety

\begin{tabular}{|c|c|c|}
\hline Operating accuracy & 201.12.1.103 & $\pm 0.5^{\circ} \mathrm{C}$ \\
\hline Skin sensor accuracy & 201.9.6.2.1.101 & $\pm 0.3^{\circ} \mathrm{C}$ \\
\hline \multicolumn{3}{|l|}{ Vital signs } \\
\hline ECG rate & Fluke biomedical & $\pm 5 \%$ \\
\hline Respiration rate & Fluke biomedical & $\pm 5 \%$ \\
\hline NIBP & IEC 80601-1-2-30 & $\pm 10 \mathrm{mmHg}$ \\
\hline $\mathrm{SpO}_{2}$ & ISO 80601-2-61:2011 & $\pm 3 \%$ \\
\hline \multicolumn{3}{|l|}{ Defibrillator } \\
\hline Paddle continuity test & Fluke biomedical & $\leq 0.15 \Omega$ \\
\hline Heart rate accuracy & Fluke biomedical & $\pm 5 \%$ \\
\hline Recorder speed & Fluke biomedical & $\pm 4 \%$ \\
\hline Testing energy & Fluke biomedical & $\pm 15 \%$ \\
\hline Energy after $60 \mathrm{~s}$ of full charge & Fluke biomedical & $\geq 85 \%$ \\
\hline Synchronization test & Fluke biomedical & $\leq 60 \mathrm{~ms}$ \\
\hline Battery test@360 J & Fluke biomedical & $\pm 15 \%$ \\
\hline Charge time & Fluke biomedical & $\leq 15 \mathrm{~s}$ \\
\hline \multicolumn{3}{|l|}{ ECG } \\
\hline Lead alarm & Fluke biomedical & Observe \\
\hline Heart rate accuracy & IEC 60601-2-27 & $\pm 5 \%$ \\
\hline Paper speed & Fluke biomedical & $\pm 4 \%$ \\
\hline Frequency test & Fluke biomedical & Observe \\
\hline ECG artefact & Fluke biomedical & Observe \\
\hline Overshoot & Fluke biomedical & $\pm 1 \mathrm{~mm}$ \\
\hline Damping & Fluke biomedical & $\pm 1 \mathrm{~mm}$ \\
\hline Alarm test & IEC 60601-2-27 & $10 \mathrm{~s}$ \\
\hline \multicolumn{3}{|l|}{ Electrical safety test } \\
\hline Voltage live to neutral & IEC EN 62353 & $\pm 10 \%(\mathrm{~V})$ \\
\hline Voltage neutral to earth & IEC EN 62353 & $\pm 10 \%(\mathrm{~V})$ \\
\hline Voltage live to earth & IEC EN 62353 & $\pm 10 \%(\mathrm{~V})$ \\
\hline Protective earth resistance & IEC EN 62353 & $<0.3(\Omega)$ \\
\hline Insulation resistance & IEC EN 62353 & $<2 \mathrm{M}(\Omega)$ \\
\hline Enclosure leakage current closed earth & IEC EN 62353 & $\begin{array}{l}<1000 \mu \mathrm{A} \text { class I, }<500 \mu \mathrm{A} \\
\text { class II }\end{array}$ \\
\hline Applied part leakage current & IEC EN 62353 & $\begin{array}{l}<500 \mu \mathrm{A} \text { class } \mathrm{II},<50 \mu \mathrm{A} \\
\mathrm{CF}\end{array}$ \\
\hline
\end{tabular}

Table 2. Test equipment.

\begin{tabular}{llc}
\hline Measured quantity & Range & Accuracy \\
\hline Measurement of electrical safety parameters & & \\
\hline Voltage & 0 to $300 \mathrm{~V} \mathrm{ac} \mathrm{rms}$ & $\pm(2 \%+0.2 \mathrm{~V})$ \\
\hline
\end{tabular}




\begin{tabular}{|c|c|c|}
\hline Insulation resistance & $0.5 \mathrm{M} \Omega$ to $20 \mathrm{M} \Omega$ & $\pm(2 \%$ of reading $+0.2 \mathrm{M} \Omega)$ \\
\hline Current consumption & 0 to $20 \mathrm{~A}$ & $\begin{array}{l} \pm(5 \% \text { of reading }+(2 \text { counts or } 0.2 \mathrm{~A} \text {, whichever is } \\
\text { greater }))\end{array}$ \\
\hline Protective earth resistance & 0.000 to $2.999 \Omega$ & $\pm(2 \%$ of reading $+0.015 \Omega)$ \\
\hline \multicolumn{3}{|c|}{ Fluke biomedical, Vital signs simulator, ProSim8 } \\
\hline NIBP simulations & $\begin{array}{l}\text { Adult: } 60 / 30(40), 80 / 50(60) ; 100 / 65(77) ; 120 / 80 \text { (93); } \\
\text { 150/100 (117); and 200/150 (167) and 255/195 (215) }\end{array}$ & $\begin{array}{l}\text { Repeatability within } \pm 2 \text { MMHG (At maximal pulse size } \\
\text { independent of device under test) }\end{array}$ \\
\hline Leakage rate & 0 to $200 \mathrm{mmHg} / \mathrm{min}$ & $<2 \mathrm{mmHg} / \mathrm{min}$ into $500 \mathrm{ml}$ rigid volume \\
\hline Pressure relief & 100 to $400 \mathrm{mmHg}$ & $\pm(0.5+0.5 \mathrm{mmHg})$ \\
\hline \multirow[t]{4}{*}{ Heart rate } & $30-240$ BPM & $\pm 1 \%$ of setting \\
\hline & $35-100 \%$ with oximeter manufacturer's R-curve & \\
\hline & Saturation within UUT specific range & $\pm(1$ count + specified accuracy of the UUT $)$ \\
\hline & Saturation outside UUT specific range & monotonic with unspecified accuracy \\
\hline \multirow[t]{4}{*}{ Oxygen (\%) } & With fluke biomedical R-curves 91 to $100 \%$ & $\pm(3$ counts + specified accuracy of the UUT $)$ \\
\hline & 81 to $90 \%$ & $\pm(5$ counts + specified accuracy of the UUT $)$ \\
\hline & 71 to $80 \%$ & $\pm(7$ counts + specified accuracy of the UUT $)$ \\
\hline & Below $71 \%$ & monotonic with unspecified accuracy \\
\hline Puls rate & $30-250$ BPM & $\pm 1 \%$ of setting \\
\hline ECG rate & $10 \mathrm{BPM}$ to $360 \mathrm{BPM}$ & $\pm 1 \%$ of setting \\
\hline Pulse wave & $30,60 \mathrm{BPM}$, with $60 \mathrm{~ms}$ pulse width & $\pm 1 \%$ of setting \\
\hline Square wave & $0.125,2.0,2.5 \mathrm{~Hz}$ & $\pm 1 \%$ of setting \\
\hline Triangle wave & $0.125,2.0,2.5 \mathrm{~Hz}$ & $\pm 1 \%$ of setting \\
\hline Sine wave & $0.05,0.5,1,2,5,10,25,30,40,50,60,100$ and $150 \mathrm{~Hz}$ & $\pm 1 \%$ of setting \\
\hline Width & 8 to $20 \mathrm{~ms}$ & $\pm(1 \%+1 \mathrm{~ms})$ \\
\hline Respiration rate & 10 to $150 \mathrm{BrPM}$ & $\pm 5 \%$ \\
\hline \multicolumn{3}{|c|}{ Fluke biomedical, Defibrillator/Transcutaneous pacer analyzer, Impulse 7000DP } \\
\hline Delivered energy & $0.1-600$ Joule & $\pm(1 \%+0.1 \mathrm{~J})$ \\
\hline Synchronization & -120 to $+380 \mathrm{~ms}$ & $\pm 1 \mathrm{~ms}$ \\
\hline Charge time & $0.1 \mathrm{~s}$ to $100 \mathrm{~s}$ & $\pm 0.05 \mathrm{~s}$ \\
\hline \multicolumn{3}{|c|}{ Calibration of infant incubators and radiant warmer } \\
\hline Temperature & 5 to $70^{\circ} \mathrm{C}$ & $+0.5^{\circ} \mathrm{C}+1 \mathrm{LSB}$ \\
\hline Relative humidity & $0-100 \% \mathrm{RH}$ & $\pm 5.3 \% \mathrm{RH}$ \\
\hline Sound level & $30-80 \mathrm{DB}$ & $+5 \mathrm{dbA}$ \\
\hline Air flow & 0.1 to $0.7 \mathrm{~m} / \mathrm{s}$ & $\pm 0.1 \mathrm{~m} / \mathrm{s}$ \\
\hline
\end{tabular}

\section{Results}

Test results are analyzed and validated according to relative international standard and the manufacture specification. The medical devices under test with all valid test results are assigned to, which contains all the DUTs that passed visual, safety and performance test, while the DUT that failed to pass any of the tests will be assigned to as shown in Table 3 . The errors of each type of medical device were investigated. The percentage of errors is shown in Table 4. Thus, it is possible to see which error occurs in which ratio. Figures 2 to 7 show the results of each type of selected devices. 


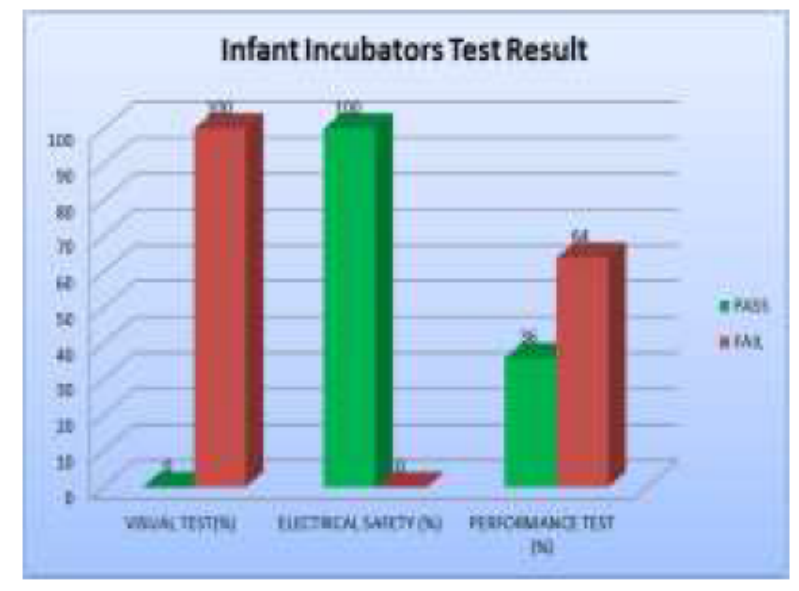

Figure 2. Results of infant incubators.

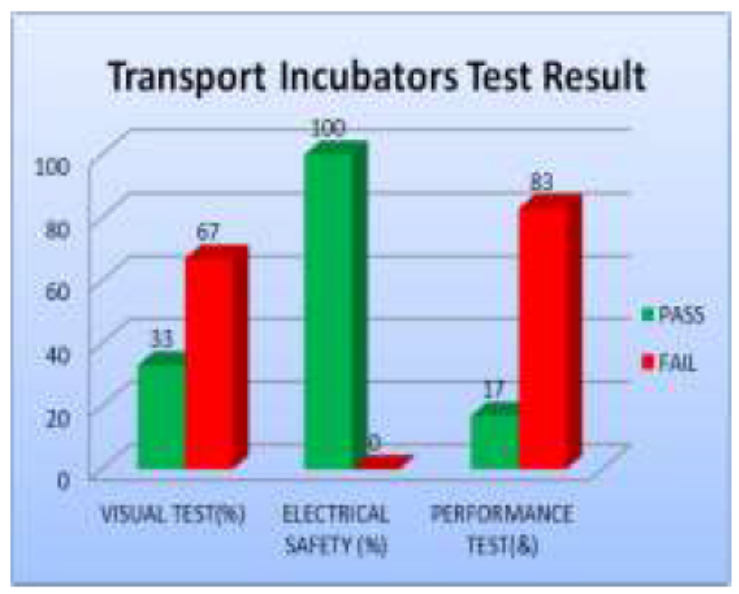

Figure 3. Results of transport incubators.

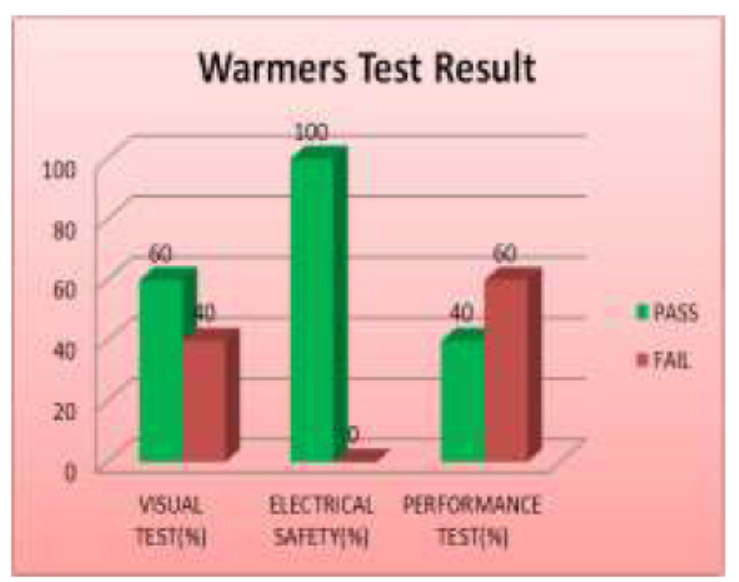

Figure 4. Results of warmers.

In examine the efficiency of medical devices to ensure their performance in accordance with international standards and to determine deviations in measurement. The study showed that there is a difference in the results of visual test, safety test and performance test. $22 \%$ of the total assets of infant incubators were tested and $100 \%$ of them failed the visual test, $0 \%$ of them failed safety test and $64 \%$ of them failed the performance test as showed in Figure 2.

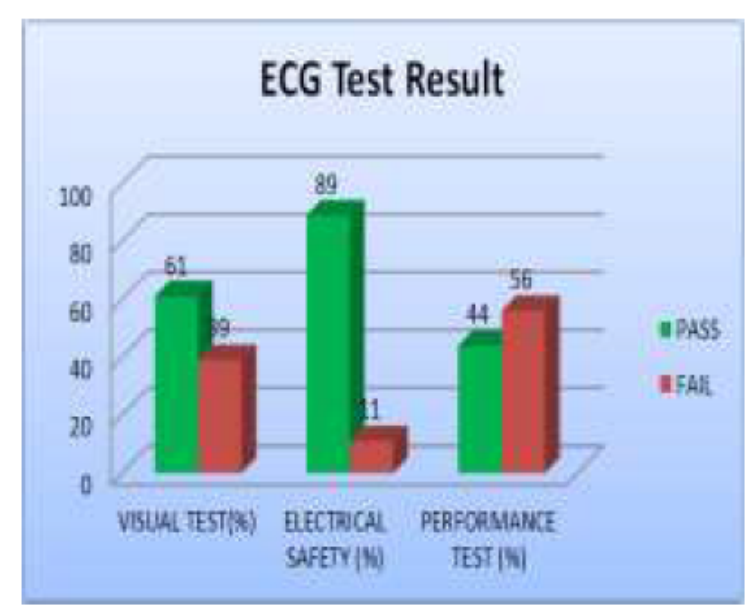

Figure 5. Results of ECG.

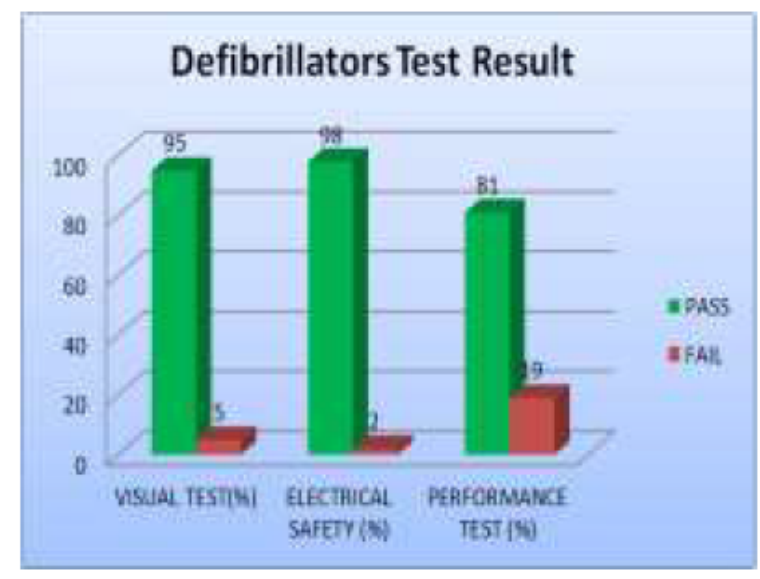

Figure 6. Results of defibrillators.

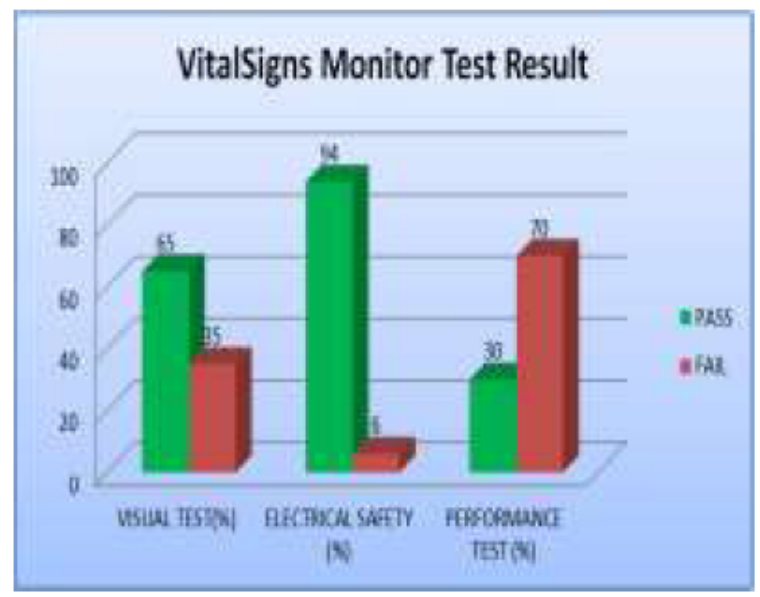

Figure 7. Results of vital signs monitor.

All transport incubators devices were tested and 67\% of them failed visual test, $0 \%$ of them failed safety test, and $83 \%$ of them failed performance test as shown in Figure 3. 19\% of total assets of warmers were tested and $40 \%$ of them failed visual test; $0 \%$ of them failed safety and $60 \%$ of them failed performance test as shown in Figure 4. 
Table 3. Test results of DUT failed.

\begin{tabular}{llll}
\hline Medical devices & Visual test $\%$ & Safety test \% & Performance test \% \\
\hline Infant incubators & 100 & 0 & 64 \\
\hline Transport incubators & 67 & 0 & 83 \\
\hline Warmers & 40 & 0 & 60 \\
\hline ECG & 39 & 11 & 56 \\
\hline Defibrillator & 5 & 2 & 19 \\
\hline VitalSigns monitor & 35 & 6 & 70 \\
\hline
\end{tabular}

In our examination, $19 \%$ of total asset of ECG machine were tested and $39 \%$ of them failed visual test; $11 \%$ of them failed in safety and $56 \%$ of them failed performance test as shown in Figure $5.20 \%$ of the total assets of defibrillator were tested and $5 \%$ of them failed the visual test, $2 \%$ of them were failed safety test and $19 \%$ of them failed the performance test as showed in Figure 6. A 20\% sample of total asset of vital signs monitors were tested and $35 \%$ of them failed visual test, $6 \%$ of safety test, and $70 \%$ failed performance test as shown in Figure 7.

The study reflects a method that can be used to improve the efficiency of medical devices and ensure the quality of their performance in accordance with international standards. We were also able to identify problems for each devices and lack of suitability to international standards.

Table 4. The errors of failed DUT.

\begin{tabular}{|c|c|c|c|}
\hline DUT & Total of DUT & Errors & $\begin{array}{l}\text { Number } \\
\text { errors (\%) }\end{array}$ \\
\hline \multirow{6}{*}{ Infant incubators } & \multirow{6}{*}{11} & No skin probe & 73 \\
\hline & & Fan noise & 36 \\
\hline & & Display & 18 \\
\hline & & $\begin{array}{l}\text { Temp control } \\
\text { damage }\end{array}$ & 9 \\
\hline & & Water tank & 18 \\
\hline & & Skin accuracy & 9 \\
\hline \multirow{2}{*}{ Transport incubators } & \multirow{2}{*}{6} & Skin probe & 34 \\
\hline & & Windo cover & 17 \\
\hline \multirow{3}{*}{ Warmers } & \multirow{3}{*}{10} & No skin probe & 40 \\
\hline & & Heater stop@33 C & 10 \\
\hline & & Control key damage & 10 \\
\hline \multirow{3}{*}{ ECG } & \multirow{3}{*}{18} & Lead broken & 28 \\
\hline & & Power cable & 11 \\
\hline & & Printer broken & 6 \\
\hline \multirow{2}{*}{ Defibrillator } & \multirow{2}{*}{42} & $\begin{array}{l}\text { Recorder speed } \\
\text { need to adjust }\end{array}$ & 17 \\
\hline & & $\begin{array}{l}\text { Printed } \\
\text { Unclear }\end{array}$ & 7 \\
\hline
\end{tabular}

\begin{tabular}{|c|c|c|c|}
\hline & & \\
\hline & & $\begin{array}{l}\text { Protective earth } \\
\text { resistance }\end{array}$ & 2 \\
\hline \multirow{5}{*}{ VitalSigns monitor } & \multirow{5}{*}{125} & $\begin{array}{l}\text { Caring } \\
\text { broken }\end{array}$ & 2 \\
\hline & & NIBP cuff & 4 \\
\hline & & ECG lead & 3 \\
\hline & & Power cable & 4 \\
\hline & & Printer broken & 0.8 \\
\hline
\end{tabular}

\section{Discussion}

The study shows a large percentage of devices failed the performance test, with the transport incubator having the highest percentage $(83.3 \%)$ and the defibrillators having the lowest $(19 \%)$. This is a very high percentage since these devices are high risk and/or life saving devices, which questions their reliability and may compromise patient safety and health.

In comparing the current research with similar studies that have been carried out, among which are Sezdi in Turkey and Almir et al. in Bosnia and Herzegovina.

Table 5. Test results by Sezdi.

\begin{tabular}{llll}
\hline Medical devices & Total asset & $\begin{array}{l}\text { Number of devices failed the } \\
\text { test }\end{array}$ & Fail \% \\
\hline Infant incubators & 34 & 6 & 18 \\
\hline Defibrillator & 52 & 9 & 17 \\
\hline Ventilator & 99 & 12 & 12 \\
\hline Anesthesia unit & 53 & 23 & 43 \\
\hline Electrosurgical unit & 59 & 14 & 24 \\
\hline Physiological monitor & 245 & 51 & 21 \\
\hline Total & 542 & 115 & $21 \%$ \\
\hline
\end{tabular}

A study conducted by Sezdi on high risk group medical devices (Table 5) used at the Departments of Operation Room and Intensive Care in Cerrahpasa, Faculty of Medicine in Istanbul University. Results showed 115 medical devices were signed as "Failed" of the total 542 medical devices from different departments which represents $21 \%$ [22].

The study by Badnjevic et al. involved 3 clinical centres, 25 hospitals, 63 health centres and 320 private health institutions in Bosnia and Herzegovina over the course of $1 \mathrm{y}$. The outcome of this study showed 23 of 90 devices (26\%) doesn't meet the error limits requirements (Table 6) [23].

Table 6. Test results by Badnjević et al.

\begin{tabular}{lllc}
\hline Medical devices & $\begin{array}{l}\text { Total } \\
\text { asset }\end{array}$ & $\begin{array}{l}\text { Number of devices failed the } \\
\text { test }\end{array}$ & Fail \% \\
\hline ECG Devices & 26 & 6 & 23 \\
\hline Defibrillator & 15 & 6 & 40
\end{tabular}




\begin{tabular}{lccc}
\hline Anesthesia machine & 7 & 2 & 29 \\
\hline Incubator & 17 & 4 & 24 \\
\hline Respirator & 7 & 0 & 0 \\
\hline Patient monitor & 5 & 1 & 20 \\
\hline $\begin{array}{l}\text { Therapeutic } \\
\text { ultrasound }\end{array}$ & 14 & 6 & $43 \%$ \\
\hline Total & 90 & 23 & 26 \\
\hline
\end{tabular}

\section{Conclusions}

The objective of this study is to examine the impact of calibration of medical devices performance and patient's safety. The study found $34 \%$ of the total selected sample of medical devices under test from major hospital in Saudi Arabia failed in visual test, $5 \%$ failed safety test and $58 \%$ failed performance test. This is higher than those reported by the previous two studies conducted by Sezdi et al. which reported failure rate of $21 \%$ and $26 \%$ respectively.

The study reflects a method that can be used to improve the efficiency of medical devices and ensure the quality of their performance in accordance with international standards. We were also able to identify the problems of each device and lack of suitability to international standards. Accordingly, the expansion of the study in the future to cover all medical devices is very important in order to assess the performance of medical devices in all departments of the hospital. It is important to note that the problems related to the performance test of medical devices in this study did not cause serious accidents or resulted in death, but these devices do not meet international standards and use can be dangerous to the patient because of the risk associated with their performance.

\section{References}

1. Ernesto I. Testing of mechanical ventilators and infant incubators in healthcare institutions. Technol Health Care 2017; 27.

2. Saleh A. Medical devices and patient safety. J Analytical Pharm Res 2016; 2.

3. Martin JT. Review of medical metrology lack of quality control of physical medical measurements. Med Meterol Rev 2016.

4. FDA. Understanding barriers to medical devices quality. US Food Drug Administration 2011.

5. Lejla G, Almir B. Medical devices in legal metrology framework. 3rd WHO Global Forum on Medical Devices 2017.

6. IEC 60601-1. Medical electrical devices-Part 1: General requirements for basic safety and essential performance. Int Organisation Standardisation 2012; 1.

7. IEC 62353. Medical electrical devices-Recurrent test and test after repair of medical electrical devices. Int Organisation Standardisation 2007.

8. BS EN ISO/IEC 17025. General requirements for the competence of testing and calibration laboratories. Int Organisation Standardisation 2005.

9. Rigel M. An introduction to electrical safety testing in accordance with IEC 62353. Rigel Med 2015.

10. Tobey Clark J, Michael L, Leah R. Medical devices quality assurance: inspection program development and procedures. Fluke Biomed Instrumentation Technical Services Univ Vermont 2.

11. ECRI. Biomedical Benchmark. The inspection and preventive maintenance system procedures (IPM). SCRIBD 2014.

12. IEC 60601-2-19. Medical electrical devices-Part 2-19: Particular requirements for the basic safety and essential performance of infant incubators (Edition 2.0). Int Organisation Standardisation 2009.

13. IEC 60601-2-20. Medical electrical devices-Part 2-20: Particular requirements for the basic safety and essential performance of infant transport incubators (Edition 2.0). Int Organisation Standardisation 2009.

14. IEC 60601-2-27. Medical electrical devices- Part 2-27: Particular requirements for the basic safety and essential performance of electrocardiographic monitoring devices (Edition 3.0). Int Organisation Standardisation 2011.

15. IEC 60601-2-31. Medical electrical devices-Part 2-31: Particular requirements for the basic safety and essential performance of external cardiac pacemakers with internal power source. Int Organisation Standardisation 2011.

16. IEC 60601-2-34. Medical electrical devices-Part 2-34: Particular requirements for the basic safety and essential performance of invasive blood pressure monitoring devices (Edition 3.0). Int Organisation Standardisation 2011.

17. IEC 60601-2-47. Medical electrical devices-Part 2-47: Particular requirements for the basic safety and essential performance of ambulatory electrocardiographic systems. Int Organisation Standardisation 2012.

18. IEC 60601-2-49. Medical electrical devices-Part 2-49: Particular requirements for the basic safety and essential performance of multifunction patient monitoring devices. Int Organisation Standardisation 2011.

19. ISO 80601-2-61. Medical electrical devices-Part 2-61: Particular requirements for basic safety and essential performance of pulse oximeter devices (First edition). Int Organisation Standardisation 2011.

20. ISO 80601-2-56. Medical electrical devices-Part 2-56: Particular requirements for basic safety and essential performance of clinical thermometers for body temperature measurement (First edition). Int Organisation Standardisation 2009.

21. ANSI/AAMI EC13. Cardiac monitors, heart rate meters, and alarms. Int Organisation Standardisation 2002.

22. Mana S. Performance analysis for medical devices, biomedical devices technology program. Biomed Eng Res 2013; 2: 139-146. 
23. Almir B, Lejla G, Dušanka B, Zijad D. Medical devices in legal metrology, 4th Mediterranean conference on embedded computing. IEEE 2015.

\section{*Correspondence to}

Altayyar Saleh S

Department of Biomedical Technology

College of Applied Medical Sciences

King Saud University

Riyadh

Saudi Arabia 